\title{
Aggrecan, link protein and tenascin-R are essential components of the perineuronal net to protect neurons against iron-induced oxidative stress
}

\author{
A Suttkus ${ }^{1}$, S Rohn ${ }^{1}$, S Weigel ${ }^{1}$, P Glöckner ${ }^{1}$, T Arendt $^{\star, 1}$ and M Morawski ${ }^{1,2}$
}

In Alzheimer's disease (AD), different types of neurons and different brain areas show differential patterns of vulnerability towards neurofibrillary degeneration, which provides the basis for a highly predictive profile of disease progression throughout the brain that now is widely accepted for neuropathological staging. In previous studies we could demonstrate that in AD cortical and subcortical neurons are constantly less frequently affected by neurofibrillary degeneration if they are enwrapped by a specialized form of the hyaluronan-based extracellular matrix (ECM), the so called 'perineuronal net' (PN). PNs are basically composed of large aggregating chondroitin sulphate proteoglycans connected to a hyaluronan backbone, stabilized by link proteins and cross-linked via tenascin-R (TN-R). Under experimental conditions in mice, PN-ensheathed neurons are better protected against iron-induced neurodegeneration than neurons without PN. Still, it remains unclear whether these neuroprotective effects are directly mediated by the PNs or are associated with some other mechanism in these neurons unrelated to PNs. To identify molecular components that essentially mediate the neuroprotective aspect on PN-ensheathed neurons, we comparatively analysed neuronal degeneration induced by a single injection of $\mathrm{FeCl}_{3}$ on four different mice knockout strains, each being deficient for a different component of PNs. Aggrecan, link protein and TN-R were identified to be essential for the neuroprotective properties of PN, whereas the contribution of brevican was negligible. Our findings indicate that the protection of PN-ensheathed neurons is directly mediated by the net structure and that both the high negative charge and the correct interaction of net components are essential for their neuroprotective function.

Cell Death and Disease (2014) 5, e1119; doi:10.1038/cddis.2014.25; published online 13 March 2014

Subject Category: Neuroscience

Cell death in the nervous system, irrespective of whether it is caused by inflammation, ischaemia or primary degeneration, selectively affects rather constantly special types of neurons, whereas others are spared even under advanced disease conditions. AD represents one of the best-characterized paradigms for this principle of 'selective neuronal vulnerability'. Here, different types of neurons and different brain areas show a differential pattern of vulnerability towards neurofibrillary degeneration, which provides the basis for a highly predictive profile of disease progression throughout the brain, which now is widely accepted for neuropathologically staging. ${ }^{1}$ In previous studies we could demonstrate that in AD cortical and subcortical neurons are constantly less frequently affected by neurofibrillary degeneration if they are enwrapped by a specialized form of the ECM, the so-called PN. ${ }^{2,3}$ Recent studies identified another stable form of ECM in the central nervous system. Those small, round or oval structures, called axonal coats, are mostly found to surround synaptic sites on dendrites and cell bodies. ${ }^{3-7}$
PNs are large meshworks surrounding neuronal cells composed of ECM molecules, which after their first description in the 1890s by Golgi and Ramón Y Cajal were largely neglected and re-discovered only around 30 years ago. ${ }^{8-10}$ PNs are composed of chondroitin sulphate proteoglycans (CSPGs), including lecticans (aggrecan, brevican, neurocan and versican), phosphacan and hyaluronan, TN-R and link proteins (cartilage link protein Crtl-1/HAPLN-1 and brain link protein Bral2/HAPLN-4). ${ }^{11-14}$ These components interact with each other and with hyaluronan, which provides the molecular backbone of the PN, thereby creating a stable scaffold around cell bodies and proximal dendrites of neurons ${ }^{15,16}$ (for the principal structure of PN in the barrel field cortex see Figure 1a).

The role of the PN is not completely understood. Different functions have been suggested derived from the functional properties of their molecular constituents. PNs contain both CSPGs and TN-R, known to inhibit neurite outgrowth, and may thus result in a restriction of neuronal and synaptic

\footnotetext{
${ }^{1}$ University of Leipzig, Department for Molecular and Cellular Mechanisms of Neurodegeneration, Paul Flechsig Institute for Brain Research, Jahnallee 59, Leipzig 04109, Germany and ${ }^{2}$ SUNY Upstate Medical University, Department of Neuroscience and Physiology, WH 3240750 East Adams Street, Syracuse, NY 13210, USA ${ }^{*}$ Corresponding author: T Arendt, University of Leipzig, Department for Molecular and Cellular Mechanisms of Neurodegeneration, Paul Flechsig Institute of Brain Research, Jahnallee 59, Leipzig 04109, Germany. Tel: +49 341 9725721; Fax: +49 341 9725729; E-mail: aret@medizin.uni-leipzig.de Keywords: proteoglycan; metal; neuroprotection; extracellular matrix

Abbreviations: ACAN, aggrecan encoding gene; AD, Alzheimer's disease; BCAN, brevican encoding gene; Bral2, brain link protein 2; CNS, central nervous system; Crtl-1, cartilage link protein 1; CSPGs, chondroitin sulphate proteoglycans; ECM, extracellular matrix; GAG, glycosaminoglycan; HAG, human aggrecan; HAPLN1, hyaluronan and proteoglycan link protein 1; HSP90, heat shock protein 90; IP, intraperitoneal; KO, knockout; PBS, phosphate-buffered saline; PFA, paraformaldehyde; PN, perineuronal net; PV, parvalbumin; ROI, region of interest; TN-R, tenascin-R; WFA, Wisteria floribunda agglutinin; WT, wild type

Received 01.8.13; revised 04.12.13; accepted 08.1.14; Edited by A Verkhratsky
} 


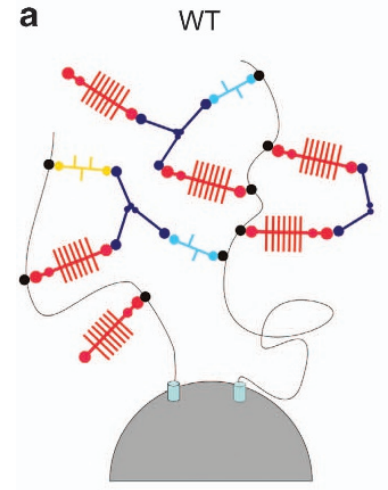

b

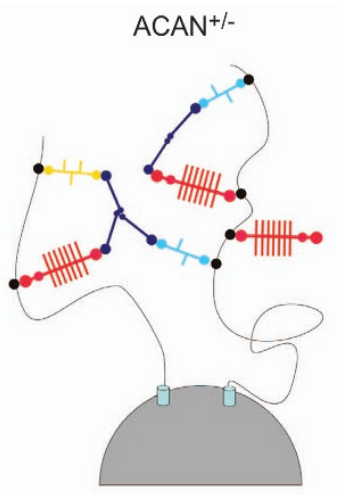

d

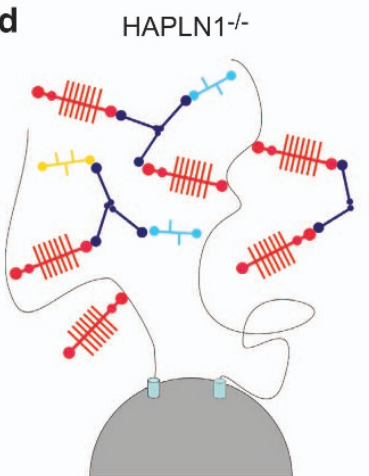

e

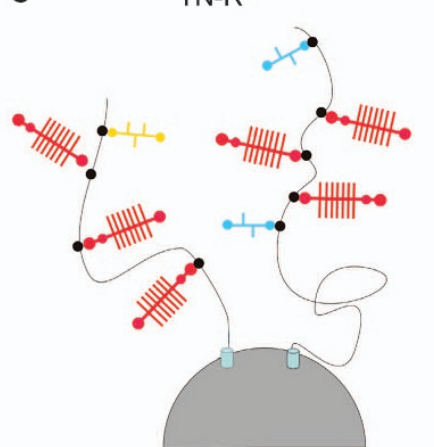

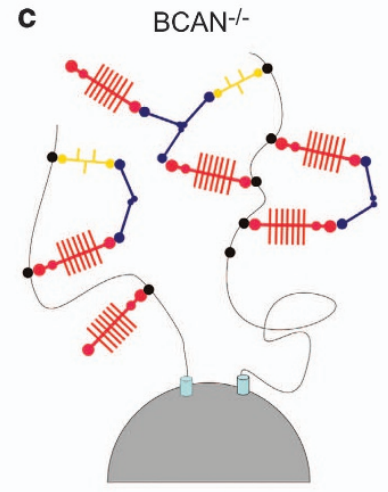

Key

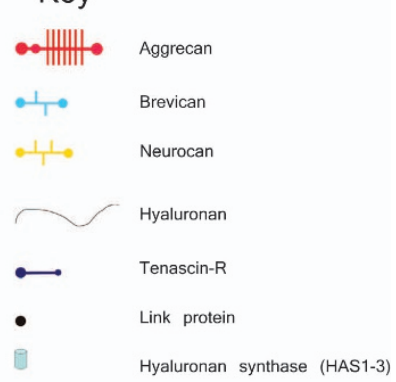

Figure 1 Schematic synopsis of molecular composition of PNs in the barrel field cortex. (a) Hyaluronan synthases are located at the neuronal surface, synthesizing and secreting hyaluronan to the perineuronal area. Members of the lectican family (aggrecan, neurocan and brevican) bind to this hyaluronic backbone. So far, versican could not be identified as part of PN in the barrel field cortex. Binding of CSPGs to hyaluronan is stabilized by the link proteins. TN-R crosslinks the lecticans to form stable PNs. (b) PNs of heterozygous deficient aggrecan mice ( $\mathrm{ACAN}^{+/-}$) lacking about $50 \%$ of the originally included aggrecan. (c) In mice lacking brevican (BCAN ${ }^{-1-}$ ), neurocan partially compensates for it. (d) PNs of mice lacking link protein (HAPLN1 ${ }^{-1-}$ ) or TN-R ${ }^{-1-}$ (e) are structured loosely, preventing the formation of stable meshworks

plasticity. $9,17,18$ In addition, the glycoprotein components of the PNs carry numerous glycosaminoglycan (GAG) side chains, which are long unbranched polymers of repetitive disaccharide units consisting of an amino-sugar ( $N$-acetylgalactosamine). ${ }^{19}$ Sulphate groups attached to these GAGs in concert with the negatively charged hyaluronic acid generate a highly polyanionic microenvironment around $\mathrm{PN}$ ensheathed neurons. ${ }^{20,21}$ Most likely, they can, thus, interact with calcium, potassium and sodium ions, providing a local 'buffer reservoir' for physiologically relevant cations. In cortical areas, $\mathrm{PN}$-wearing interneurons are often associated with the calcium-binding protein parvalbumin (PV). These interneurons are identified as highly active and fast spiking, which requires high ionic currents and a tightly regulated ion homeostasis. The anionic features of PNs surrounding these neurons might contribute to meet these requirements. ${ }^{20,22-25}$

In addition to this physiological mechanism, the polyanionic components might also interact with ions of potential pathophysiological relevance such as iron ions involved in generating oxidative stress. ${ }^{20,22,26,27}$ We have, thus, put forward the hypothesis that PNs, through scavenging and binding of redoxactive iron, are able to reduce the potentially deleterious local oxidative potential in the neuronal microenvironment, thereby protecting neurons ensheathed by PNs against oxidative damage. ${ }^{22,28}$ In support of this suggestion, we previously observed that both in normal-aged brain and
AD neurons ensheathed by a PN are less frequently affected by lipofuscin accumulation than neurons without a net. As lipofuscin is an intralysosomal pigment composed of cross-linked proteins and lipids generated by iron-catalysed oxidative processes, this finding suggests a neuroprotective function of PNs against neurodegeneration induced by oxidative stress. ${ }^{22,23,29-31}$ In an effort to validate our hypothesis, we analysed the effects of iron injection into mice brain on neurons with or without PN. We could show that net-associated neurons were less severely affected by degeneration than neurons without $\mathrm{PNs}^{28}$ Still, it remains unclear whether these neuroprotective effects are directly mediated by the PN or its components are associated with some other mechanism in these neurons unrelated to PNs.

Therefore, in the present study, we intended, first, to verify that PNs are directly involved in the neuroprotective mechanism and second, to identify those molecular components of PNs that essentially mediate these neuroprotective properties. To this end, we comparatively analysed the sequalae of iron-induced neuronal damage in four different mice knockout strains, each deficient for a different molecular component of the $\mathrm{PN}$, such as aggrecan $\left(\mathrm{ACAN}^{+/-}\right)$, brevican $\left(\mathrm{BCAN}^{-/-}\right)$, tenascin- $\mathrm{R}\left(\mathrm{TN}-\mathrm{R}^{-/-}\right.$) or link protein 1 (HAPLN1 ${ }^{-/-}$). (for the principal structure of PNs in the used mouse models see Figures $1 \mathrm{~b}-\mathrm{e})$. We could identify aggrecan, tenascin and link protein HAPLN1 as PN components essential to mediate their 
neuroprotective properties. These results clearly show a direct albeit differential contribution of ECM components to the neuroprotective function of PNs.

\section{Results}

In the present study, we analysed whether the neuroprotective properties associated with the presence of $\mathrm{PN}$, previously observed, ${ }^{28}$ are directly mediated by the PN or whether the PN only provides a surrogate marker of some unidentified mechanism. Further, we defined the molecular components of the PN that are essential to mediate these neuroprotective properties. To this end, protection of $\mathrm{PN}$-ensheathed neurons was differentially analysed after microinjection of $\mathrm{FeCl}_{3}$ into the barrel field cortex, in four different mice knockout strains, each being deficient for a different component of PNs, such as aggrecan $\left(\mathrm{ACAN}^{+/-}\right)$, lacking brevican $\left(\mathrm{BCAN}^{-/-}\right)$, link protein (HAPLN1 ${ }^{-1-}$ ) or tenascin-R $\left(\mathrm{TN}^{-\mathrm{R}^{-/-}}\right)^{-}$knockout mice.

PN-associated phenotypes of different mice knockout strains. The constitutive deficiency of defined molecular net components had some phenotypic effects on the appearance but not on the number of PNs in all tested mouse strains. The phenotypic appearance of PNs in mice either lacking brevican $\left(\mathrm{BCAN}^{-1-}\right)$ or being deficient in aggrecan $\left(\mathrm{ACAN}^{+/-}\right)$did not differ noticeably from wild type, enwrapping the neuronal soma as well as the proximal dendrites as a sharply contoured, lattice-like meshwork. PNs of mice lacking link protein $\left(\mathrm{HAPLN1}^{-/-}\right)$or tenascin- $\mathrm{R}\left(\mathrm{TN}^{-\mathrm{R}^{-/-}}{ }^{-1}\right.$ in contrast appeared somewhat more fuzzy and granular with reduced staining around dendrites (Figures $2 a-e)$. Similar observations were made previously. ${ }^{13,32-34}$

To determine whether the deficiency of defined molecular components of PNs had a constitutive effect on the number of PNs, we assessed the numerical density of neurons with and without $\mathrm{PN}$ in the barrel field cortex of each different mouse knockout strain (Figures 2a1-e1). There were no effects on the total numerical density of neurons in any of the knockout strains compared with wild type.

Next, we analysed whether different knockout genotypes had any effects on the number of neurons enwrapped by PNs. In addition, $\mathrm{PN}$-associated neurons were stratified according to the presence or absence of PV. In wild-type animals, PN-ensheathed neurons amounted to about $10 \%$ of all neurons, with about half of them (49\%) containing PV. This was in accordance with Nowicka et al. ${ }^{35}$ The lack of brevican as well as the deficit of aggrecan had no effects on the presence of $\mathrm{PN}$-ensheathed neurons. In contrast, netassociated neurons as well as net-associated PV positive neurons were significantly reduced in number in HAPLN1 ${ }^{-/}$ and $\mathrm{TN}^{-\mathrm{R}^{-1-}}$ mice. The ratio of $\mathrm{PN}$-associated neurons with and without $\mathrm{PV}$ was only shifted in $\mathrm{TN}-\mathrm{R}^{-/-}$mice, with a significant reduction of $\mathrm{PV}$ containing $\mathrm{PN}$-ensheathed neurons.

Knockout genotypes of $\mathrm{PN}$-associated components have differential effects on brain lesions. To define molecular components, essential to mediate the neuroprotective properties of PNs, we investigated the effects of deficiency of a defined PN component on the size of experimentally induced brain lesion. After injection of $\mathrm{FeCl}_{3}$ into the barrel cortex, a widespread degeneration of brain tissue was observed around the injection site in all mice strains, which could clearly be delineated by Fluoro-Jade B staining (Figures 3a-e). Quantification of the lesion size, however, clearly showed that all transgenic mice strains showed significantly larger degeneration than wild-type mice (Figure 3f). A lack of tenascin-R (TN-R ${ }^{-1-}$ ) mediated the most extensive degeneration with a radius of about $1500 \mu \mathrm{m}$ of the affected cross-sectional area. Somewhat smaller dimensions of degeneration were observed in mice lacking link protein 1 (HAPLN1 $\left.1^{-/-}\right)$, aggrecan $\left(\mathrm{ACAN}^{+/-}\right)$or brevican $\left(\mathrm{BCAN}^{-/-}\right)$with average radii of the lesion between 1300 and $1350 \mu \mathrm{m}$. However, no significant differences could be measured. Control injections with $0.9 \% \mathrm{NaCl}$ revealed only marginal lesions with maximum degeneration radii of $200 \mu \mathrm{m}$ (data not shown). Again, no significant differences could be investigated within the different mice strains or in comparison to WT mice.

Aggrecan, TN-R and link protein 1 are essential for the neuroprotective properties of PNs. Next, we analysed in our lesion paradigm whether neurons ensheathed by a PN lacking a specific matrix compound were affected differentially compared with neurons without PN. To this end, we labelled the net structure either with Wisteria floribunda agglutinin (WFA), which binds to chondroitin sulphate side chains most likely on aggrecan, ${ }^{36-38}$ or with an antibody that labels the aggrecan core protein (HAG), the main proteoglycan component of PNs. ${ }^{4,10,18,39}$

Three independent methods were used to detect degenerating neurons, namely Fluoro-Jade B staining, a caspase-3 antibody and an antibody against $\mathrm{H} 2 \mathrm{AX}$ in combination with histochemical labelling of the net structures. The vast majority of degenerating neurons, detected with any of these methods, were devoid of PNs (Figure 4). Only occasionally, PNensheathed neurons were positive for a stain detecting degenerating neurons. Still these rare cases, as exemplified in Figure 4, clearly ruled out any systemic bias with respect to accessibility of the detection dye to neurons ensheathed by PN compared with neurons without PN.

To obtain a quantitative measure on the effects of $\mathrm{PNs}$ upon neurodegeneration, degenerating neurons were quantified after a combination of PN labelling by either WFA histochemistry or anti-HAG immunocytochemistry with Fluoro-Jade B and NeuN (Figure 5).

In Figures 6a-e the percentage of Fluoro-Jade B-positive neurons without PN (light grey), in regard to the total number of neurons without PN, is compared with the percentage of Fluoro-Jade B-positive neurons with a PN (dark grey), relating to the total number of neurons ensheathed by a PN. The results of cell counting revealed clear differences for affected neurons, depending on the knockout mice strain. In brevican knockout mice (BCAN ${ }^{-1-}$ ), $\mathrm{PN}$-associated neurons were significantly less frequently affected by degeneration than neurons without PN. This effect was independent of the detection method of PNs (Figure 6c). In aggrecan-deficient mice $\left(\mathrm{ACAN}^{+/-}\right)$, neurons ensheathed by a $\mathrm{PN}$, visualized with WFA, were also less frequently affected by degeneration compared with neurons without PN (Figure 6b). This difference 

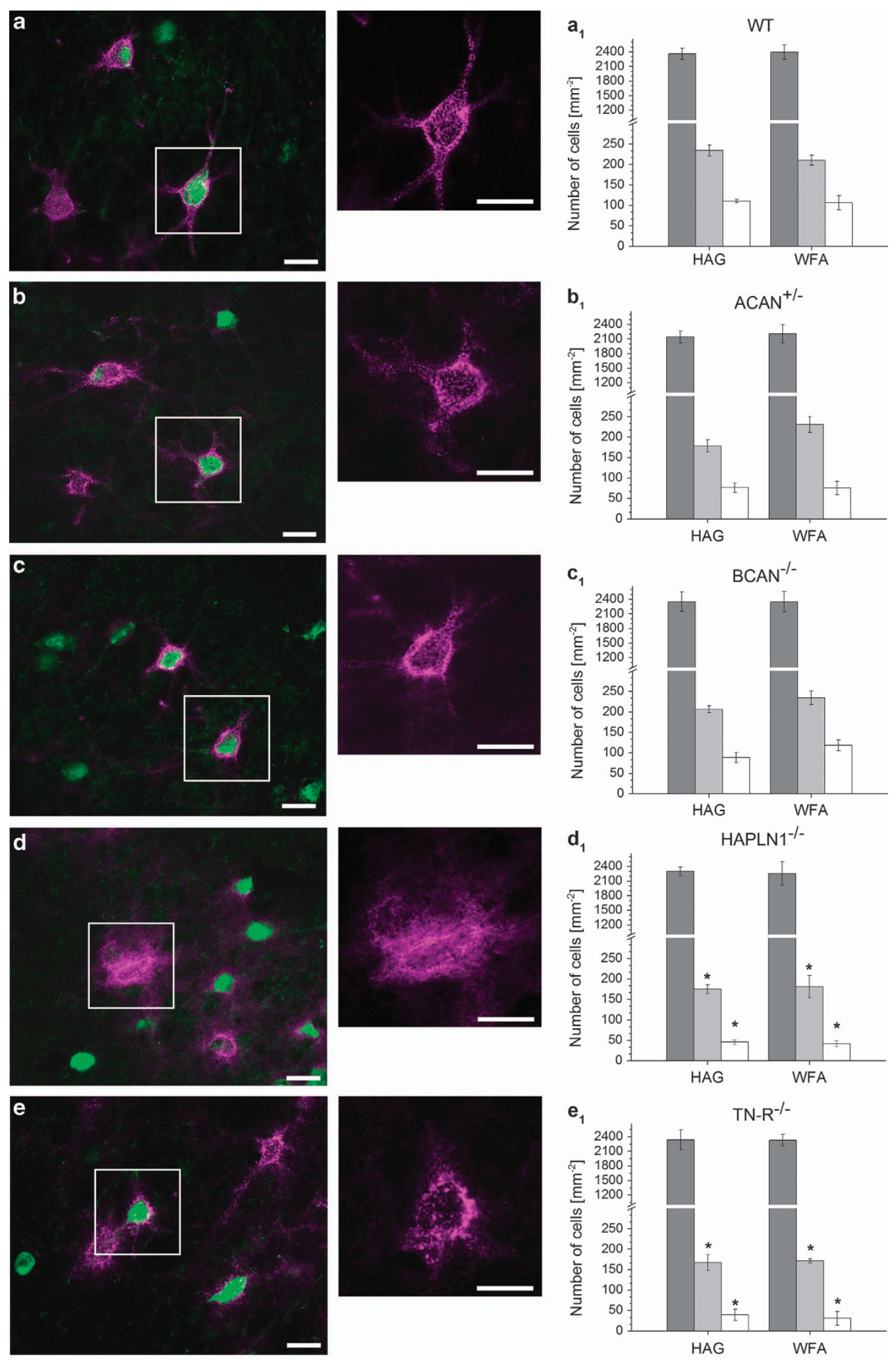

Key

$\square$ total neural population neural population with $\mathrm{PN}$

neural population with $\mathrm{PN}$, parvalbumin associated 
disappeared, however, when aggrecan immunocytochemistry (HAG) was used for detection of PNs. Differences in vulnerability between neurons with and without PN were abolished completely in mice lacking either the link protein 1 (HAPLN-1 $^{-/-}$) (Figure 6d) or tenascin-R $\left(\mathrm{TN}-\mathrm{R}^{-1-}\right.$ ) (Figure 6e).

To evaluate any potential contribution of $\mathrm{PV}$ to the neuroprotective properties on $\mathrm{PN}$-ensheathed neurons, triple-stained sections, labelled for PV and Fluoro-Jade B in combination with either HAG or WFA were analysed likewise for differential effects of degeneration. As summarized in Figures 6a1-e1, no increased protection of PV-associated net-wearing neurons could be observed. In $\mathrm{BCAN}^{-/-}$mice, PN-associated neurons with PV detected by WFA as well as HAG were even significantly more frequently affected than those without PV.
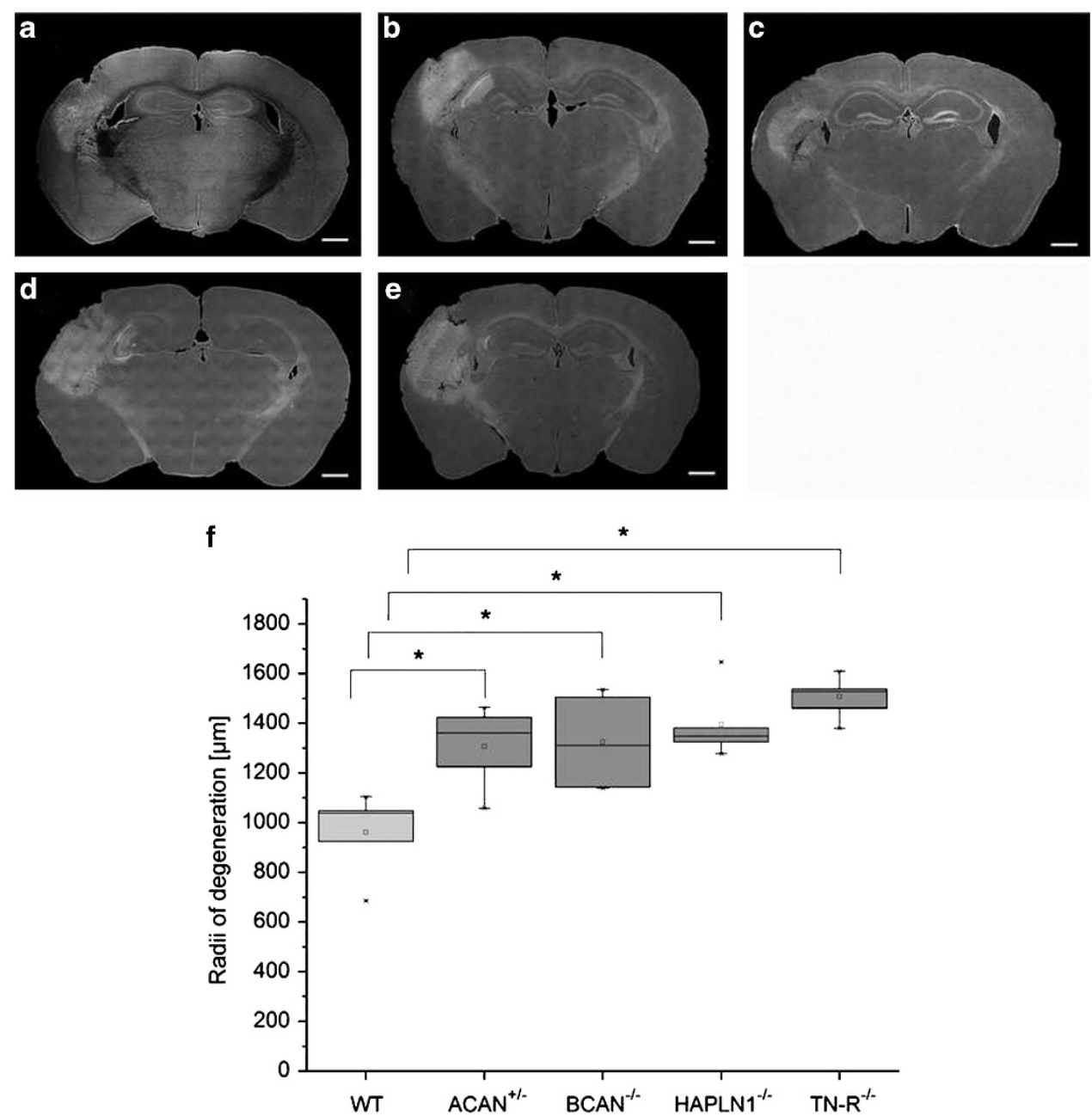

Figure 3 Extent of neurodegeneration induced by single-sided injection of $\mathrm{FeCl}_{3}$ into the barrel field cortex of mice knockout strains lacking specific components of PNs. (a-e) Typical examples of coronal sections cut through the lesion at its maximal extension. A volume of $0.2 \mu \mathrm{l} 20 \mathrm{mM} \mathrm{FeCl}$ was injected into the left barrel field cortex; degenerating cells were detected by Fluoro-Jade B staining $24 \mathrm{~h}$ later. Note that brain tissue volume affected by degeneration is significantly different in different mice strains. (a) WT; (b) $\mathrm{ACAN}^{+1-}$; (c) $\mathrm{BCAN}^{-1-}$; (d) HAPLN-1 ${ }^{-1-}$, (e) TN-R ${ }^{-1-}$. Scale bar $500 \mu \mathrm{m}$. Quantification of lesion size determined on serial sections after staining with Fluoro-Jade B (f). In all mice knockout strains, lesion size was significantly larger than in wild type (WT). A lack of tenascin (TN- ${ }^{-1-}$ ) results in the most extensive spreading of degeneration. In brevican knockout mice ( $\mathrm{BCAN}^{-1-}$ ), heterozygous aggrecan knockout mice $\left(\mathrm{ACAN}^{+1-}\right)$ and mice lacking the link protein $1\left(\mathrm{HAPLN}-1^{-1-}\right)$, lesion size is somewhat smaller. Data are expressed as mean values. Statistical analysis by Mann-Whitney test, $n=5$. ${ }^{*} P<0.05$

Figure 2 Morphological and numerical appearance of neurons with and without PN in different mice knockout strains compared with wild type, detected in layers II and III of the barrel field cortex. Double fluorescence staining of PNs by WFA (pink) and the Ca-binding protein PV (green). Sections of wild-type mice (a) show intensely labelled, robust lattice-like structures enwrapping the neuronal soma and the proximal dendrites; PN of mice deficient for aggrecan (ACAN ${ }^{+/-}$) (b) or brevican (BCAN ${ }^{-1-}$ ) (c) look slightly fuzzy, but not disturbed. In contrast, PN of mice lacking the cartilage link protein (HAPLN1 ${ }^{-1}$ ) are attenuated and disturbed with almost no staining around dendrites. (d) Furthermore, Tenascin-R (TN-R ${ }^{-1-}$ ) knockout mice (e) display granular structures with lesser overall staining around dendrites. (a1-e1) Numerical density of neurons stained by NeuN (dark grey), of PN-associated neurons detected by (WFA, light grey) or an antibody against aggrecan core protein (HAG, light grey) and of PN-associated neurons expressing PV (white) in the barrel field cortex. In mice deficient for aggrecan (b1), link protein 1 (d1) or TN-R (e1), numbers of PN-associated as well as PN-associated, PV-expressing neurons were significantly reduced. The lack of brevican (c1) had no effect on the numerical density of neurons. Data are mean values, \pm S.D. Statistical analysis by Mann-Whitney test, $n=5$. ${ }^{*} P<0.05$, scale bar $20 \mu \mathrm{m}$ 

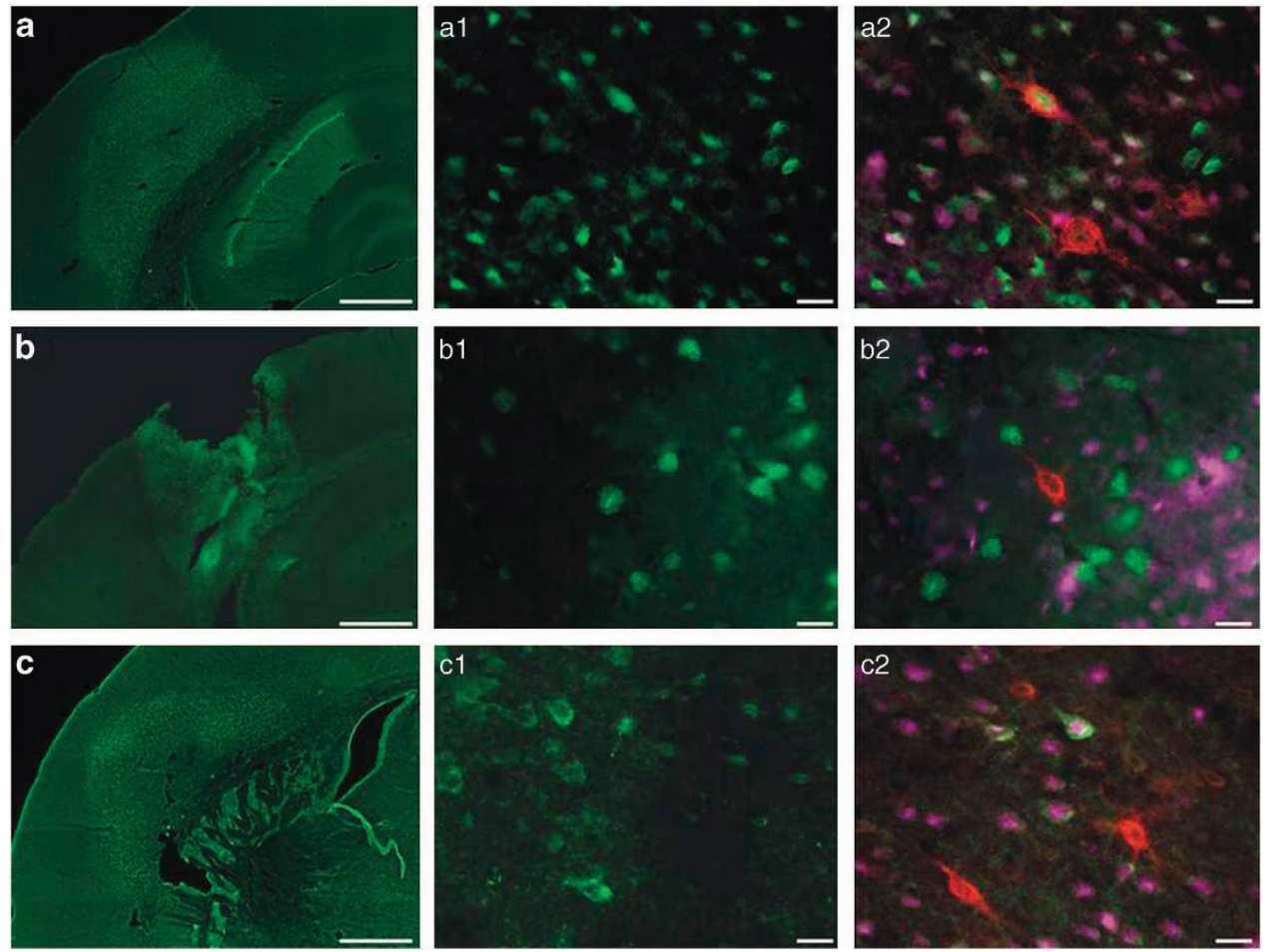

Figure 4 Different detection methods for neuronal death in the barrel field cortex. Degenerated cells after injection of $\mathrm{FeCl}_{3}$ can be visualized with Fluoro-Jade $\mathrm{B}$ (a), an active caspase-3 antibody (b) and an antibody against H2AX (c). All three markers visualize degenerated cells to a similar extent. A microscopic picture with a higher magnification of the different markers (a1-c1), followed by the combination with WFA histochemistry (red) and the neuronal marker NeuN (pink) (a2-c2) allows a determination of affected neurons with and without PN. Scale bar (a-c) $500 \mu \mathrm{m}$ and (a1-c2) $20 \mu \mathrm{m}$

Aggrecan is upregulated after $\mathrm{FeCl}_{3}$ induced injury. In addition, we investigated the aggrecan expression in the injured CNS by western blotting. For this analysis, the hemisphere of iron-induced lesion as well as the correspondent contralateral hemisphere were dissected and prepared for subsequent processing. Protein extracts were run in a $6 \%$ gel. Western blot analysis with the anti-aggrecan antibody AB1031 revealed a single band at $\sim 450 \mathrm{kDa}$ in injured and uninjured hemispheres (Figure 7a). A comparative quantification with TINA software (Raytest, Straubenhardt, Germany) revealed higher contents of aggrecan in iron-injected hemispheres for all tested mouse lines, with significant differences in mice lacking brevican or HAPLN1 (Figure 7b). Here, the content of aggrecan is increased by $45 \%\left(\mathrm{BCAN}^{-1-}\right)$ and $67 \%$ (HAPLN1 ${ }^{-l-}$ ). Furthermore, a significant decrease of aggrecan in mice heterozygous deficient for aggrecan $\left(\mathrm{ACAN}^{+/-}\right)$could be confirmed. Here, the overall content of aggrecan is reduced by $60 \%$ compared with the analysed tissue of WT mice.

\section{Discussion}

In the present study, we defined molecular components of PNs that essentially mediate neuroprotective properties. Using a comparative approach, provoking a neurotoxic insult in four different transgenic mice strains, each lacking or being deficient in a different molecular component of PNs, we could identify clear differences with respect to both lesion size and neuronal population affected by degeneration. Neurons ensheathed by a PN in wild-type mice were less frequently affected by degeneration than neurons without PN. These neuroprotective properties associated with the presence of PNs were lost when TN-R and HAPLN-1 were lacking, while the deficiency of aggrecan had a partial effect and the lack of brevican had no effect.

In addition, mice deficient for TN-R, link protein 1, brevican or aggrecan showed a significantly higher spreading of degeneration than wild-type mice after single sided injection of $\mathrm{FeCl}_{3}$. This increase in tissue volume, which is affected by degeneration, was observed for all mice strains lacking a specific matrix component. On the background of previous reports on the contribution of lecticans ${ }^{40,41}$ and $T N-R^{42}$ to the diffusion and hydration properties of the neural ECM, a facilitated diffusion of dissociated $\mathrm{FeCl}_{3}$ due to the lack of $\mathrm{PN}$ components most likely accounts for these effects.

Our main interest was the identification of hyaluronanbased ECM molecules, which essentially mediate the neuroprotective properties of PNs. Aggrecan is one of the main components of the ECM and the key component of the PNs. ${ }^{43,44}$ It is the largest member of the lectican family and carries up to 100 negatively charged chondroitin sulphate side chains. ${ }^{10,45}$ Thus, aggrecan interacting with hyaluronan, also highly negatively charged, mainly contributes to the polyanionic character of the PN. Our data show that PN detected by the aggrecan antibody HAG in mice heterozygous deficient for aggrecan $\left(\mathrm{ACAN}^{+/-}\right.$), have lost their neuroprotective properties. Most likely, the content of aggrecan in these PNs is reduced below a critical level, which is not sufficient to exert 

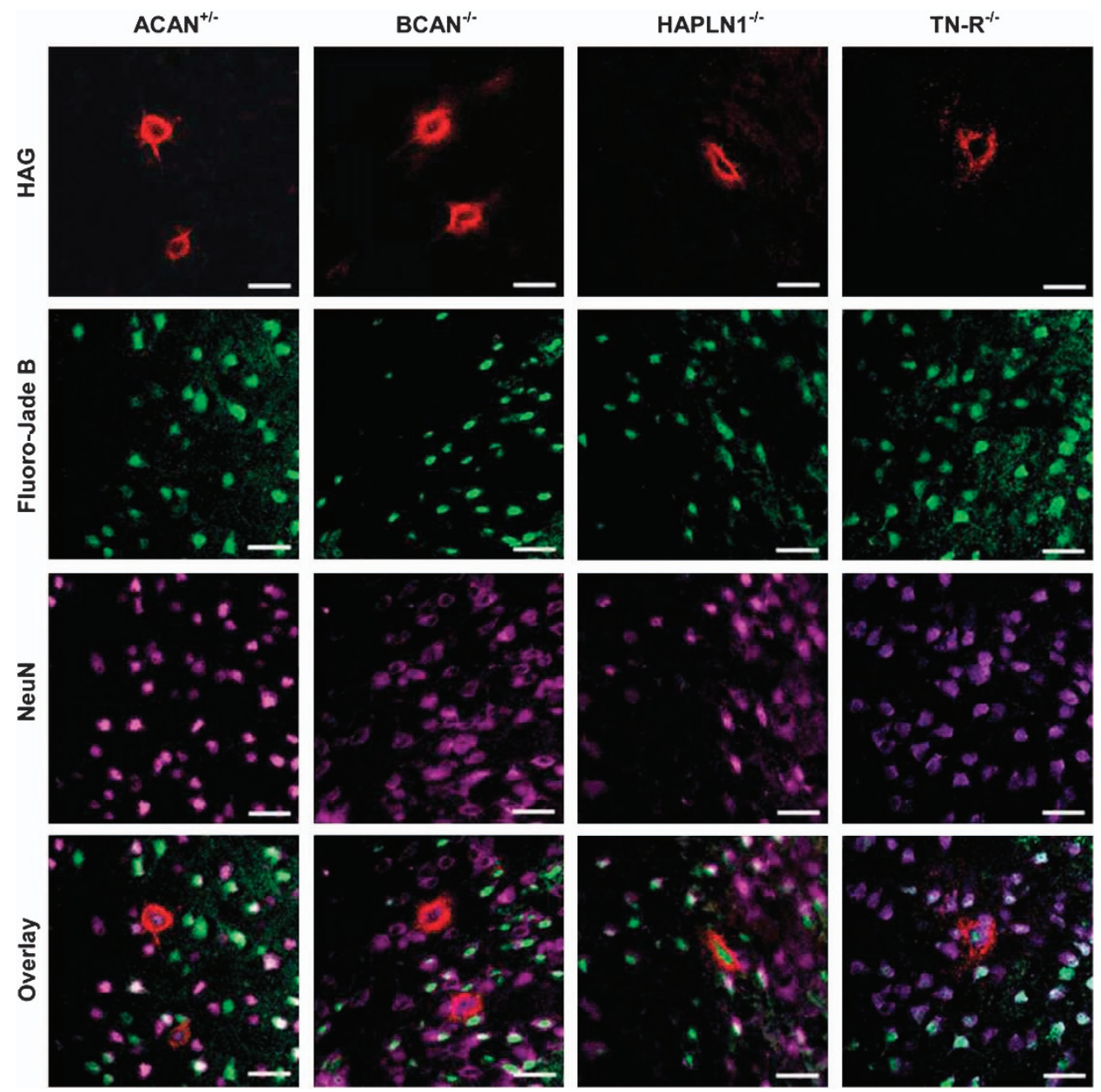

Figure 5 Detection of death neurons with and without PN in different mice knockout strains detected by triple staining. PNs were visualized by HAG (red), degenerating cells were labelled by Fluoro-Jade B (green) and neurons were detected by NeuN (pink). Merged images were used for quantitative analysis. Scale bar $20 \mu \mathrm{m}$

the neuroprotective effects. ${ }^{44}$ Neurons with PNs, however, detected in the same mice with WFA were significantly less frequently affected by iron-induced degeneration. This might indicate that other matrix compounds providing binding sites for WFA might partially compensate for the loss of aggrecan. In addition, it might show that WFA binding, indicating the presence of highly charged anionic binding sites, provides a signature for the neuroprotective properties of PNs. The hypothesis that aggrecan is one of the key factors for mediating neuroprotective properties is supported by the data received from the western blotting analysis. Here, the decreased level of aggrecan in $\mathrm{ACAN}^{+/-}$mice in comparison with WT mice could be demonstrated. Furthermore, the content of aggrecan in the hemisphere containing the iron injection is increased compared with the not-injected hemisphere in all mouse lines. Here, significant differences could be shown for mice lacking brevican and link protein HAPLN1. However, this clear trend could confirm a certain neuroprotection of aggrecan itself. An upregulation of aggrecan could already be seen in studies concerning neurodegenerative diseases. Lendvai et al. ${ }^{7}$ could demonstrate increased aggrecan contents in the hippocampal formation of $A D$ patients as well as in the hippocampal tissue of the $A D$ mouse model APPswe/PS1dE9. ${ }^{7}$ They suggested that this upregulation of aggrecan could be based on neuroprotective mechanisms. An upregulation of PN components has so far been shown only for versican and neurocan in the context of forming a glial scar after brain injury. ${ }^{14}$ However, versican and neurocan most likely do not contribute to neuroprotective mechanisms, but rather to the inhibition of axonal outgrowth and regeneration, respectively. So, aggrecan represents the most potential CSPG in the context of protective processes.

Another proteoglycan component we investigated is brevican. Here, brevican showed the smallest contribution to neuroprotective features of PNs, if any. This could be demonstrated irrespectively of whether the remaining net was detected by WFA binding sites or HAG. Brevican is an important proteoglycan in the adult rodent and to some extent part of the PN. It is mainly enriched in the perisynaptic structure of the axonal coats while it contributes only marginally to enwrapping of the neuronal soma (unpublished results). Brakebusch et al. ${ }^{32}$ could demonstrate a certain upregulation of neurocan in brevican knockout mice, which may partially compensate for the loss of brevican. But, the expression of neurocan, highly upregulated during embryonic development, indicates a strong influence of neurocan mainly during early 

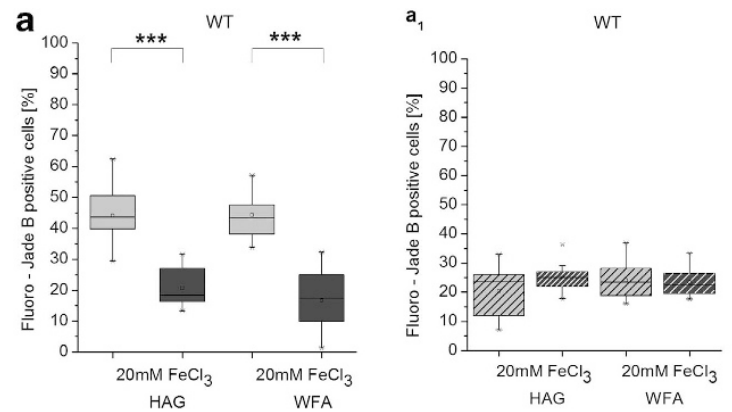

Key
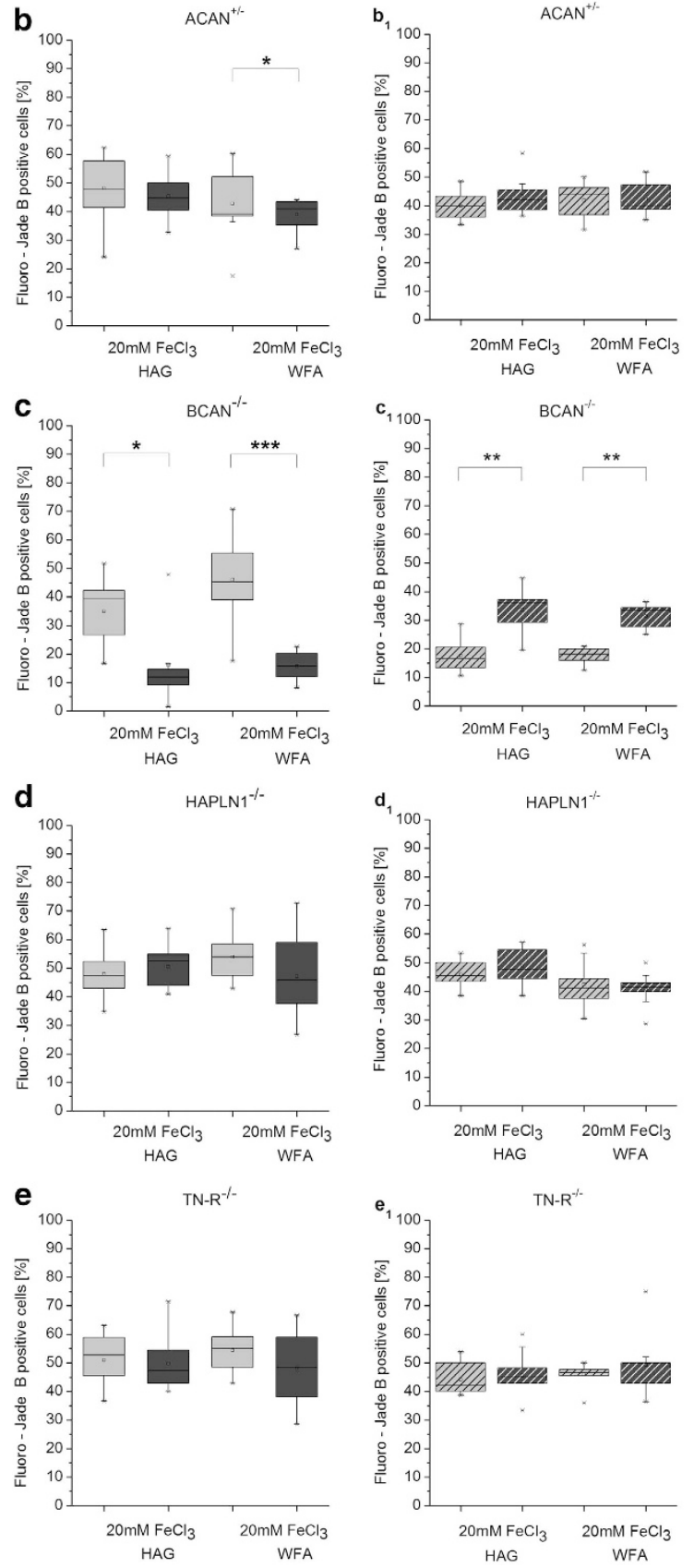
developmental processes. Brevican, however, is highly expressed during the formation of PNs until the end of the critical period. Neurocan and brevican have a largely complementary expression profile during ontogenesis. Thus, it is assumable that the upregulation of neurocan in $\mathrm{BCAN}^{-/-}$ mice beyond embryonic development may be in order to reduce developmental deficits. So, it is comprehensible that the loss of brevican does not have a major effect on the 'shielding' properties of PNs against oxidative damage. ${ }^{46-48}$

The next matrix component we have analysed is the link protein HAPLN-1. HAPLN-1, next to HAPLN-4, stabilizes the interaction between hyaluronan and CSPGs by binding to both components. ${ }^{49}$ Of the several PN elements, HAPLN1 starts to be expressed exactly at the time PNs begin to develop. So, it might be a trigger for PN development. Furthermore, animals lacking HAPLN-1 do not form normally shaped PNs. PNs of HAPLN1 knockout mice are diffuse and seem to be less close to the plasma membrane than those of wild-type mice. ${ }^{13}$ Our experiments show that PNs lacking HAPLN1 have completely lost their neuroprotective properties. HAPLN1, thus, represents a matrix component that is essential for this function of PNs.
Results obtained on mice lacking tenascin-R (TN-R ${ }^{-/-}$) were similar to those of HAPLN-1 ${ }^{-1-}$ mice. As a large ECM glycoprotein, TN-R participates in macromolecular organization of PNs. ${ }^{50}$ It interacts with the cell surface as well as with CSPGs, including aggrecan, versican, neurocan and, with highest affinity, brevican. ${ }^{51}$ While the general histology appeared to be unaffected in TN-R-deficient mice, changes were observed in the shape and appearance of PNs, like in the HAPLN-1 knockouts. They showed a reduced WFA-staining intensity and were characterized by a more granular and less punctuate structure. ${ }^{33}$ In addition, these alterations were accompanied by a reduction of immunohistochemical staining intensity in other major matrix components, such as hyaluronan, neurocan, brevican and phosphacan. ${ }^{34}$ Altogether, these structural and molecular changes of the ECM might directly affect the physiology of neurons. This includes a disturbed synaptic stability as well as an inefficient maintenance of the ionhomeostasis.$^{52}$ Our present data show that $\mathrm{TN}-\mathrm{R}$ is also essential for the neuroprotective properties of PNs.

In summary, our findings indicate that the different ECM components of PNs contribute differently to their protective

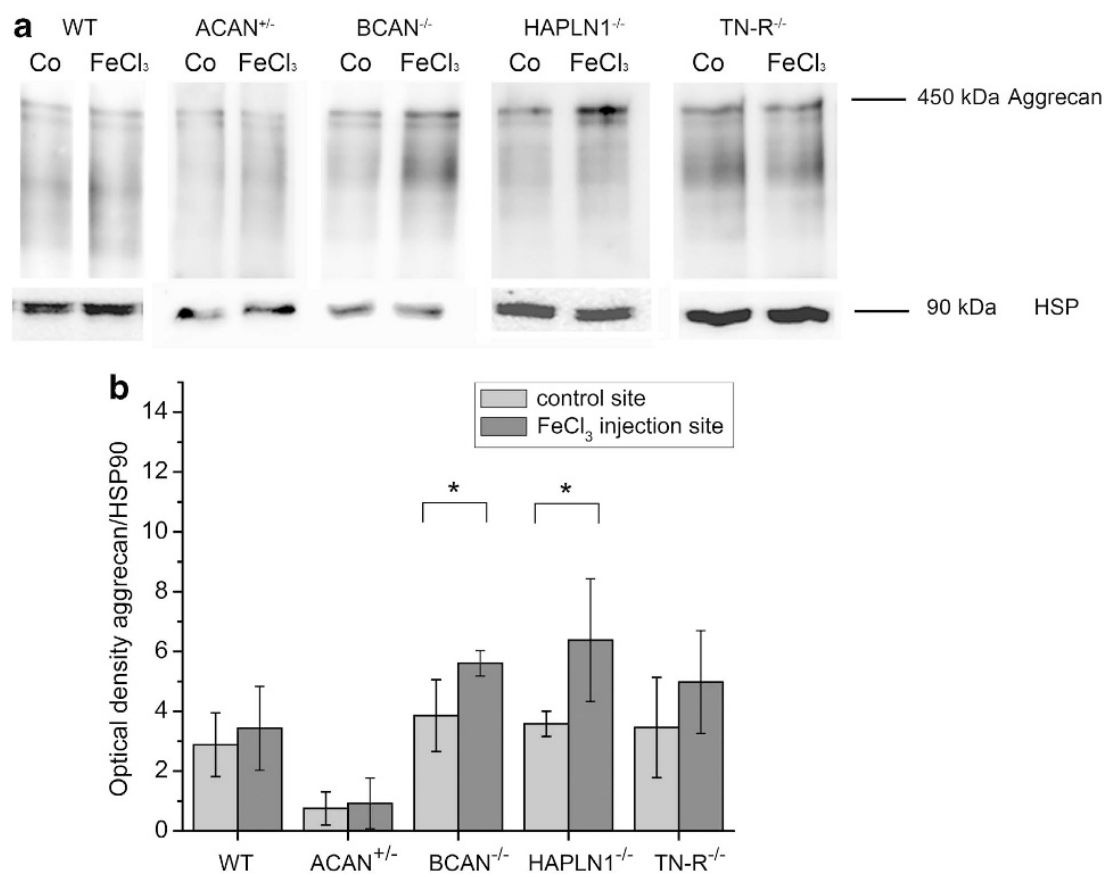

Figure 7 Western blot analysis of aggrecan contents. Protein extracts ( $30 \mu \mathrm{g} / \mathrm{lane})$ from homogenized neuronal sections from the ipsilateral site of injection were compared with the contralateral control site. Samples were subjected to SDS PAGE in a 6\% gel. Blots were probed by use of an antibody against aggrecan (AB1031) (a). Mean \pm S.D. intensity of chemiluminescence was quantified for bands at $450 \mathrm{kDa}(\mathbf{b})$ in relation to the bands of HSP90. An upregulation of aggrecan was evident with significant increases in $\mathrm{BCAN}^{-1-}$ and HAPLN1 ${ }^{-1-}$ mice. Statistical analysis by Mann-Whitney test, $n=4{ }^{*} P<0.05$

Figure 6 Neuronal degeneration after injection of $\mathrm{FeCl}_{3}$ into the barrel field cortex separately quantified for neurones with and without $\mathrm{PN}$, respectively, for the presence or absence of PV. PNs were visualized by either anti-HAG immunocytochemistry (left) or WFA lectin histochemistry (right). In WT mice (a), PN-associated neurons are significantly protected compared with neurons without PN. This difference can still be detected in mice lacking brevican (BCAN ${ }^{-1-}$, c), but is somewhat attenuated in heterozygous aggrecan (ACAN ${ }^{+/-}$, b) knockout mice. The protective effect of PNs, however, is completely abolished in mice lacking the link protein (HAPLN1 ${ }^{-1-}$, d) or tenascin-R (TN-R ${ }^{-1-}$, e). Comparing PN-associated neurons without PV to PN-associated neurons with PV reveals no contribution of PV to the neuroprotective function of PN. Brevican knockout mice (c1) indicate an even less severe affection of PN-wearing neurons without PV. No significant differences were obtained on wild-type mice (a1), heterozygous aggrecan knockout mice (b1), mice lacking the link protein (d1) or TN-R (e1). Data are expressed as mean values. Statistical analysis by Wilcoxon rank test, $n=5 .{ }^{*} P<0.05,{ }^{* *} P<0.01,{ }^{* * *} P<0.001$ 


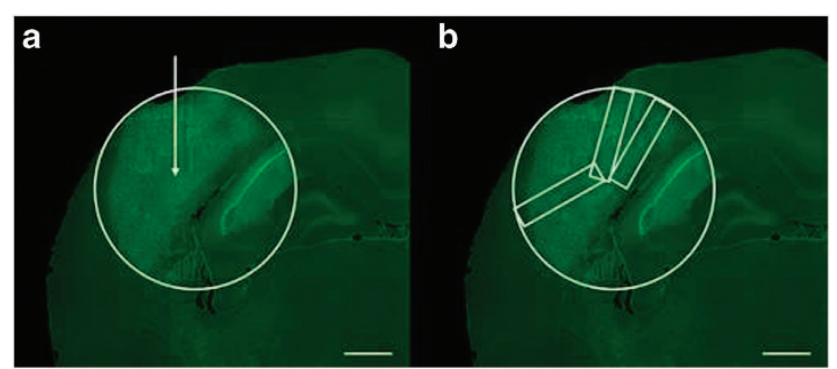

Figure 8 Illustration of the evaluation method. (a) For the quantification of neuronal death after injection of $0.2 \mu \mathrm{l} \mathrm{FeCl}$ (white arrow assigns point of injection) the largest cross-sectional area covered by Fluoro-Jade B-positive cells was defined as reference area (white circle) and copied to all analysed sections. Within this area, counting of Fluoro-Jade B-positive neurons was performed within three rectangles of a size of $0.18 \mathrm{~mm}^{2}$, randomly placed to the reference area (b). Scale bar $500 \mu \mathrm{m}$

properties. Brevican plays no direct part in protecting cells against iron-induced cell death. However, a contribution to diffusion properties is likely. On the contrary, aggrecan as the main proteoglycan component seems to be essential for protection against iron-induced cell death. Aggrecan is besides hyaluronan in charge of imparting the $\mathrm{PN}$, a polyanionic character. ${ }^{45}$ This highly negative charge could be the main aspect of the protective feature. This assumption is supported by our observation that even in heterozygous aggrecan-deficient mice the neuroprotective properties are still preserved in those PNs where sufficient negatively charged chondroitin sulphate side chains are present to generate a WFA binding. ${ }^{53}$

Further, our data indicate that the two matrix components, HAPLN1 and TN-R, are also essential for the neuroprotective function of PNs. HAPLN1 consolidates the binding of CSPGs to hyaluronan. ${ }^{13}$ Therefore, a strong connection of the CSPGs to hyaluronan seems to be an essential factor. Similar evidence was received from analysing $T N-R^{-1-}$ mice. This leads to the assumption that TN-R, by way of forming stable aggregates, has a relevant part in mediating a protective aspect of the PNs.

\section{Conclusion}

Taken together, our findings indicate that the neuroprotection of neurons ensheathed by a PN against iron-induced cell death is directly mediated by the PN and that both the high negative charge and the correct interaction of net components to form a stable barrier against ions are essential factors for their neuroprotective properties.

\footnotetext{
Materials and Methods

Animals. The following mouse lines were used in the present study: C57BL/6J mice, heterozygote aggrecan-deficient $\left(\mathrm{ACAN}^{+1-}\right)$ mice were obtained from Prof. Dr. RT Matthews (State University of New York, Upstate Medical University, Syracuse, NY, USA); ${ }^{36,43,54}$ brevican knockout mice $\left(\mathrm{BCAN}^{-1-}\right)$ mice were obtained from Dr. C Seidenbecher (Leibniz Institute for Neurobiology, Magdeburg, Germany); ${ }^{32,55}$ TN-R knockout mice (TN-R ${ }^{-1-}$ ) were obtained from Prof. Dr. M Schachner (Center for Molecular Neurobiology Hamburg (ZMNH), University of Hamburg, Germany) ${ }^{33,34}$ and link protein-deficient (HAPLN1 ${ }^{-1-}$ ) mice were obtained from Prof. Dr. J Fawcett (MRC Brain Repair, University of Cambridge, UK) and Prof Dr. T Pizzorusso (Instituto Neuroscienze CNR, Pisa, Italy). ${ }^{13,56}$ Male and female mice were bred and housed at the Medizinisch-Experimentelles
}

Zentrum of the Medical Faculty of the University of Leipzig. Animals had free access to food and water and were maintained on an artificial 12:12-h light-dark cycle under conditions of constant temperature $\left(22^{\circ} \mathrm{C}\right)$ and humidity. All experimental procedures on animals were carried out in accordance with the European Council Directive of 24 November 1986 (86/609/EEC) and had been approved by the local authorities (TVV50/10).

In vivo injection. Mice at an age of 3 months were deeply anaesthetized by intraperitoneal injection with a cocktail of ketamine $(100 \mathrm{mg} / \mathrm{kg}$, ratiopharm, Ulm, Germany) and xylazine (5 mg/kg, Rompun, Bayer, Germany). Animals, fixed to a stereotaxic apparatus (Stoelting, Wood Dale, IL, USA), received injections of $0.2 \mu \mathrm{l}$ $20 \mathrm{mM} \mathrm{FeCl}_{3}$ dissolved in a $0.9 \% \mathrm{NaCl}$ solution over $10 \mathrm{~min}$ at AP $-1.7 \mathrm{~mm}$, $\mathrm{L}+\mathrm{I}-3 \mathrm{~mm}, \mathrm{~V}-2 \mathrm{~mm}$ (from bregma and dura, head flat between bregma and dura; somatosensory cortex, barrel field S1BF according to Paxinos and Franklin $\left.{ }^{57}\right)$ using a 33-gauge needle (33/51/4, Hamilton) attached to a Hamilton syringe (Type 75-RN, Switzerland). Five animals per group were used. Animals of the control group received an equal volume of $0.9 \% \mathrm{NaCl}$, which was adjusted to the $\mathrm{pH} 4$ analogue to the $\mathrm{FeCl}_{3}$ solution $(n=3)$. Animals were analysed $24 \mathrm{~h}$ post injection.

Tissue preparation. Animals were perfused transcardially under deep $\mathrm{CO}_{2}$ anaesthesia with $0.9 \% \mathrm{NaCl}$ and $4 \%$ paraformaldehyde (PFA) in phosphatebuffered saline (PBS). Animals were decapitated; brains were removed immediately, fixed in $4 \%$ buffered PFA (24 h) and cryoprotected in 30\% sucrose with $0.01 \%$ sodium azide in PBS (48h). Series of coronal sections were cut on a freezing microtome at $30 \mu \mathrm{m}$ thickness and collected in PBS with $0.01 \%$ sodium azide.

Detection of cellular death. Degenerated neurons were detected by three different methods: staining sections with (i) Fluoro-Jade B $(0.001 \%$, Chemicon, Temecula, CA, USA), using an (ii) anti-caspase-3 antibody (AB3623, 1:50, Millipore, Darmstadt, Germany) or an (iii) antibody against phosphoS139 H2AX, a well-established marker for double-stranded DNA breaks (ab2893, 1:50, Abcam, Cambridge, UK). ${ }^{58}$ To clearly distinguish between degeneration of neurons ensheathed by PN or neurons without PN, sections were processed for one of these detection methods for degenerating neurons in combination with antibodies against aggrecan core protein (HAG7D4, mouse-anti-human aggrecan, 1:10, $\mathrm{AbD}$ Serotec, Düsseldorf, Germany) combined with biotinylated NeuN (mouseanti-NeuN clone A60, ab77315, 1:100, Millipore) or biotinylated WFA, 1:100, Sigma, Taufkirchen, Germany) combined with NeuN (mouse-anti-NeuN clone A60 MAB 377, 1:100, Millipore). Fluoro-Jade B as anionic dye specifically stains degenerating neurons by binding to a currently unknown, most likely a poly-amine, basic substance in the neuron. ${ }^{59,60}$ For counting procedures, Fluoro-Jade B was chosen because of its high technical feasibility and reproducibility. To evaluate a potential contribution of PV to the neuroprotective properties of the PNs, sections were also stained with an antibody against PV (PV25, 1:500, Swant, Marly, Switzerland) in combination with WFA and Fluoro-Jade B as well as HAG and Fluoro-Jade B.

Briefly, sections were washed in PBS, and preincubated in a blocking solution ( $2 \%$ bovine serum albumin, $0.3 \%$ casein, $0.5 \%$ donkey normal serum) for $1 \mathrm{~h}$ followed by $48 \mathrm{~h}$ incubation with the primary antibodies at $4{ }^{\circ} \mathrm{C}$. After washing, sections were incubated with Cy3-conjugated donkey-anti-mouse $\lg G(1: 300$, Dianova, Hamburg, Germany) or Cy3-conjugated donkey-anti-rabbit IgG (1:300, Dianova) and Cy5-conjugated streptavidin (1:150, Dianova) for $3 \mathrm{~h}$. Sections were washed, mounted on gelatine-coated slides and incubated with $0.001 \%$ Fluoro-Jade in $0.1 \%$ acetic acid for $30 \mathrm{~min}$. Slides were washed with distilled water, placed onto a slide warmer until fully dry, immersed in xylene for $3 \mathrm{~min}$ and coverslipped using DePeX (Serva, Heidelberg, Germany). Furthermore, combining anti-caspase-3 or anti-H2AX with WFA and NeuN requires incubation with Cy2-conjugated donkeyanti-rabbit $\lg G$ (1:250, Dianova), Cy3-conjugated streptavidin (1:300, Dianova) and Cy5-conjugated donkey-anti-mouse IgG (1:100, Dianova). Here, sections were washed, mounted on gelatine coated slides and coverslipped with Entellan (MercK, Darmstadt, Germany).

Quantification of degeneration. The extent of degeneration was examined after Fluoro-Jade B staining. For quantification of cell death, the cross-sectional tissue area covered by degenerated cells, identified after FluoroJade $B$ staining, was determined on serial sections cut throughout the entire extension of the lesion at an interval of $120 \mu \mathrm{m}$. For each animal, the largest cross-sectional area was defined as region of interest (ROI) and copied to all 
sections (Figure 8a). Fluoro-Jade B-positive neurons (detected by NeuN) were counted within three rectangles of a cross-sectional area of $0.18 \mathrm{~mm}^{2}$, randomly placed to the ROI (Figure 8b).Counts were performed using the optical fractionator method $^{8}$ on a Zeiss (Jena, Germany) Axioskop 2 plus microscope equipped with a motorized stage (Märzhäuser, Wetzlar, Germany), a Ludl MAC 5000 (LEP, Hawthorne, NY, USA) and a digital camera CX 9000 (MicroBrightField, Williston, VT, USA). Stereo Investigator software 6 (MicroBrightField) was used to analyse serial sections (19 $\mu \mathrm{m}$ thick). Statistical analyses were performed by MannWhitney test and Wilcoxon rank test.

Determination of numerical neuronal density. To evaluate the potential effects of knockout genotypes on the numerical density of neurons associated with PN, as well as on PV immunoreactive neurons, frontal brain sections of all mouse strains were investigated. The contralateral brain area of the injection site was used as internal control and analysed by using the optical fractionator method, too. Counting procedures were performed in the defined ROI as described above. Statistical analyses were done by Mann-Whitney Test.

Sample preparation for SDS-PAGE. For this analysis, mice received an injection of $0.2 \mu \mathrm{l} 20 \mathrm{mM} \mathrm{FeCl}_{3}$ into the barrel field as described previously. Twenty-four hours after injection, mice were deeply anaesthetized by $\mathrm{CO}_{2}$, decapitated, their brains removed and immediately frozen in liquid nitrogen. On a dry ice-cooled worktop, the frozen brain was dissected in $2 \mathrm{~mm}$ thick frontal sections. The slice displaying the strongest lesion was picked, bisected and transferred (separated by an injected and control hemisphere) to 2-ml tubes.

Then, hemisphere sections were homogenized on ice, using an Ultra-Turrax tube drive (IKA), in homogenization buffer $(0.02 \mathrm{M}$ Tris- $\mathrm{HCl}, 0.15 \mathrm{M} \mathrm{NaCl}, 5 \mathrm{mM} \mathrm{NaF}$, $1 \mathrm{mM} \mathrm{Na}_{3} \mathrm{VO}_{4}, 2 \mathrm{mM} \mathrm{MgCl}$, pH 7.4) containing a protease inhibitor (Complete, Roche, Mannheim, Germany). The homogenate was centrifuged at $10000 \times g$ for $14 \mathrm{~min}$ at $4^{\circ} \mathrm{C}$, followed by determination of the protein concentration in the supernatant by using the BCA Assay.

To evaluate the content of aggrecan, the main proteoglycan component of the $\mathrm{PN}$, the single supernatant was digested with $0.25 \mathrm{U}$ Chondroitinase ABC (SigmaAldrich, Hamburg, Germany) at $37^{\circ} \mathrm{C}$ for $3 \mathrm{~h}$ to erase sulphated GAG side chains of the proteoglycan core protein, according to Matthews et al. ${ }^{44}$

Electrophoresis and western blotting. To run the SDS page, the volume of the supernatant containing $30 \mu \mathrm{g}$ protein was added to the same volume of $1 \times$ SDS sample buffer and denaturized at $75^{\circ} \mathrm{C}$ for $15 \mathrm{~min}$. Then the samples were subjected to electrophoresis on $6 \%$ SDS-polyacrylamide gels with a $4.3 \%$ stacking gel and transferred to a poly vinylidene difluoride membrane (Perkin Elmer, Rodgau, Germany). The membrane was probed with anti-aggrecan (AB1031, 1:0000, Millipore) and anti-HSP 90 (4874, 1:1000, Cell Signaling, Beverly, MA, USA) antibodies and finally detected with an enhanced chemiluminescence western blot system (DNR Bio-Imaging systems, Biostep Jahnsdorf, Germany). The blots were scanned and the ratios of optical band intensities of aggrecan normalized to HSP 90 were calculated using TINA software. Experiments were done in duplicates.

\section{Conflict of Interest}

The authors declare no conflict of interest.

Acknowledgements. We thank Prof. Dr. RT Matthews, Dr. C Seidenbecher, Prof. Dr. M Schachner, Prof. Dr. J Fawcett and Prof. Dr. T Pizzorusso for providing the different transgenic mice strains. This work was granted by the European Union and the Free State of Saxony (Project: Neuron 48-038), the German Research Foundation GRK 1097 'INTERNEURO', COST Action BM1001 'Brain Extracellular Matrix in Health and Disease', German Research Foundation MO 2249/2-1 within the PP 1608, the European Union, the Free State of Saxony (grant number SAB 100154907) and the Alzheimer Forschungsinitiative e.V. (AFI \#11861) to M Morawski.

1. Braak H, Braak E. Neuropathological stageing of Alzheimer-related changes. Acta Neuropathol 1991; 82: 239-259.

2. Bruckner G, Hausen D, Hartig W, Drlicek M, Arendt T, Brauer K. Cortical areas abundant in extracellular matrix chondroitin sulphate proteoglycans are less affected by cytoskeletal changes in Alzheimer's disease. Neuroscience 1999; 92: 791-805.
3. Morawski M, Bruckner G, Jager C, Seeger G, Matthews RT, Arendt T. Involvement of perineuronal and perisynaptic extracellular matrix in Alzheimer's disease neuropathology. Brain Pathol 2012; 22: 547-561.

4. Bruckner G, Morawski M, Arendt T. Aggrecan-based extracellular matrix is an integral part of the human basal ganglia circuit. Neuroscience 2008; 151: 489-504

5. Morawski M, Bruckner G, Jager C, Seeger G, Arendt T. Neurons associated with aggrecan-based perineuronal nets are protected against tau pathology in subcortical regions in Alzheimer's disease. Neuroscience 2010; 169: 1347-1363.

6. Lendvai D, Morawski M, Bruckner G, Negyessy L, Baksa G, Glasz T et al. Perisynaptic aggrecan-based extracellular matrix coats in the human lateral geniculate body devoid of perineuronal nets. J Neurosci Res 2012; 90: 376-387.

7. Lendvai D, Morawski M, Negyessy L, Gati G, Jager C, Baksa G et al. Neurochemical mapping of the human hippocampus reveals perisynaptic matrix around functional synapses in Alzheimer's disease. Acta Neuropathol 2013; 125: 215-229.

8. Bruckner G, Delpech B, Delpech A, Girard N. Concentration of hyaluronectin and anionic glycoconjugates in perineuronal glial cell processes at GABAergic synapses of rat cerebellum. Acta Histochem Suppl 1990; 38: 161-165.

9. Hockfield S, Kalb RG, Zaremba S, Fryer H. Expression of neural proteoglycans correlates with the acquisition of mature neuronal properties in the mammalian brain. Cold Spring Harb Symp Quant Biol 1990; 55: 505-514.

10. Morawski M, Bruckner G, Arendt T, Matthews RT. Aggrecan: Beyond cartilage and into the brain. Int J Biochem Cell Biol 2012; 44: 690-693.

11. Asher RA, Scheibe RJ, Keiser HD, Bignami A. On the existence of a cartilage-like proteoglycan and link proteins in the central nervous system. Glia 1995; 13: 294-308.

12. Bekku Y, Su WD, Hirakawa S, Fassler R, Ohtsuka A, Kang JS et al. Molecular cloning of Bral2, a novel brain-specific link protein, and immunohistochemical colocalization with brevican in perineuronal nets. Mol Cell Neurosci 2003; 24: 148-159.

13. Carulli D, Pizzorusso T, Kwok JC, Putignano E, Poli A, Forostyak S et al. Animals lacking link protein have attenuated perineuronal nets and persistent plasticity. Brain 2010; 133: 2331-2347.

14. Bekku Y, Saito M, Moser M, Fuchigami M, Maehara A, Nakayama M et al. Bral2 is indispensable for the proper localization of brevican and the structural integrity of the perineuronal net in the brainstem and cerebellum. J Comp Neurol 2011; 520: 1721-1736.

15. Aspberg A, Miura R, Bourdoulous S, Shimonaka M, Heinegard D, Schachner M et al. The C-type lectin domains of lecticans, a family of aggregating chondroitin sulphate proteoglycans, bind tenascin-R by protein-protein interactions independent of carbohydrate moiety. Proc Natl Acad Sci USA 1997; 94: 10116-10121.

16. Dityatev A, Schachner M. Extracellular matrix molecules and synaptic plasticity. Nat Rev Neurosci 2003; 4: 456-468.

17. Pizzorusso T, Medini P, Berardi N, Chierzi S, Fawcett JW, Maffei L. Reactivation of ocular dominance plasticity in the adult visual cortex. Science 2002; 298: 1248-1251.

18. McRae PA, Rocco MM, Kelly G, Brumberg JC, Matthews RT. Sensory deprivation alters aggrecan and perineuronal net expression in the mouse barrel cortex. J Neurosci 2007; 27: 5405-5413.

19. lozzo RV, Murdoch AD. Proteoglycans of the extracellular environment: clues from the gene and protein side offer novel perspectives in molecular diversity and function. FASEB $J$ 1996; 10: 598-614.

20. Bruckner G, Brauer K, Hartig W, Wolff JR, Rickmann MJ, Derouiche A et al. Perineuronal nets provide a polyanionic, glia-associated form of microenvironment around certain neurons in many parts of the rat brain. Glia 1993; 8: 183-200.

21. Murakami T, Tsubouchi M, Tubouchi Y, Taguchi T, Ohtsuka A. The occurrence of neurons with strongly negatively charged surface coats in mammalian, avian, reptilian, amphibian and piscine brains. Acta Med Okayama 1994; 48: 195-197.

22. Morawski M, Bruckner MK, Riederer P, Bruckner G, Arendt T. Perineuronal nets potentially protect against oxidative stress. Exp Neurol 2004; 188: 309-315.

23. Morawski M, Reinert T, Brückner G, Wagner FE, Arendt TH, Tröger W. The binding of iron to perineuronal nets: a combined nuclear microscopy and Mössbauer study. Hyperfine Interact 2004; 159: 285-291.

24. Hartig W, Brauer K, Bigl V, Bruckner G. Chondroitin sulphate proteoglycanimmunoreactivity of lectin-labelled perineuronal nets around parvalbumin-containing neurons. Brain Res 1994; 635: 307-311.

25. Hartig W, Derouiche A, Welt K, Brauer K, Grosche J, Mader M et al. Cortical neurons immunoreactive for the potassium channel Kv3.1b subunit are predominantly surrounded by perineuronal nets presumed as a buffering system for cations. Brain Res 1999; 842: 15-29.

26. Hartig W, Singer A, Grosche J, Brauer K, Ottersen OP, Bruckner G. Perineuronal nets in the rat medial nucleus of the trapezoid body surround neurons immunoreactive for various amino acids, calcium-binding proteins and the potassium channel subunit Kv3.1b. Brain Res 2001; 899: 123-133.

27. Reinert T, Morawski M, Arendt T, Butz T. Quantitative microanalysis of perineuronal nets in brain tissue. Nucl Instrum Methods Phys Res Sect B 2003; 210: 395-400.

28. Suttkus A, Rohn S, Jäger C, Arendt T, Morawski M. Neuroprotection against iron-induced cell death by perineuronal nets-An in vivo analysis of oxidative stress. Am J Neurodegener Dis 2012; 1: 122-129.

29. Sohal RS, Brunk UT. Lipofuscin as an indicator of oxidative stress and aging. Adv Exp Med Biol 1989; 266: 17-26. 
30. Canas N, Valero T, Villarroya M, Montell E, Verges J, Garcia AG et al. Chondroitin sulfate protects SH-SY5Y cells from oxidative stress by inducing heme oxygenase-1 via phosphatidylinositol 3-kinase/Akt. J Pharmacol Exp Ther 2007; 323: 946-953.

31. Cabungcal JH, Steullet $P$, Morishita H, Kraftsik R, Cuenod M, Hensch TK et al. Perineuronal nets protect fast-spiking interneurons against oxidative stress. Proc Natl Acad Sci USA 2013; 110: 9130-9135.

32. Brakebusch $\mathrm{C}$, Seidenbecher $\mathrm{Cl}$, Asztely $\mathrm{F}$, Rauch $\mathrm{U}$, Matthies $\mathrm{H}$, Meyer $\mathrm{H}$ et al Brevican-deficient mice display impaired hippocampal CA1 long-term potentiation but show no obvious deficits in learning and memory. Mol Cell Biol 2002; 22: 7417-7427.

33. Weber $P$, Bartsch U, Rasband MN, Czaniera R, Lang Y, Bluethmann $\mathrm{H}$ et al. Mice deficient for tenascin-R display alterations of the extracellular matrix and decreased axonal conduction velocities in the CNS. J Neurosci 1999; 19: 4245-4262.

34. Bruckner G, Grosche J, Schmidt S, Hartig W, Margolis RU, Delpech B et al. Postnatal development of perineuronal nets in wild-type mice and in a mutant deficient in tenascin- $R$. J Comp Neurol 2000; 428: 616-629.

35. Nowicka D, Soulsby S, Skangiel-Kramska J, Glazewski S. Parvalbumin-containing neurons, perineuronal nets and experience-dependent plasticity in murine barrel cortex. Eur J Neurosci 2009; 30: 2053-2063.

36. Giamanco KA, Morawski M, Matthews RT. Perineuronal net formation and structure in aggrecan knockout mice. Neuroscience 2010; 170: 1314-1327.

37. Bruckner G, Seeger G, Brauer K, Hartig W, Kacza J, Bigl V. Cortical areas are revealed by distribution patterns of proteoglycan components and parvalbumin in the Mongolian gerbil and rat. Brain Res 1994; 658: 67-86.

38. Hartig W, Brauer K, Bruckner G. Wisteria floribunda agglutinin-labelled nets surround parvalbumin-containing neurons. Neuroreport 1992; 3: 869-872.

39. Virgintino D, Perissinotto D, Girolamo F, Mucignat MT, Montanini L, Errede M et al. Differential distribution of aggrecan isoforms in perineuronal nets of the human cerebral cortex. J Cell Mol Med 2009; 13: 3151-3173.

40. Sykova E. Extracellular space volume and geometry of the rat brain after ischemia and central injury. Adv Neurol 1997; 73: 121-135.

41. Hrabetova S, Masri D, Tao L, Xiao F, Nicholson C. Calcium diffusion enhanced after cleavage of negatively charged components of brain extracellular matrix by chondroitinase ABC. J Physiol 2009; 587: 4029-4049.

42. Sykova E, Vorisek I, Mazel T, Antonova T, Schachner M. Reduced extracellular space in the brain of tenascin-R- and HNK-1-sulphotransferase deficient mice. Eur J Neurosci 2005; 22: $1873-1880$.

43. Giamanco KA, Matthews RT. Deconstructing the perineuronal net: cellular contributions and molecular composition of the neuronal extracellular matrix. Neuroscience 2012; 218: 367-384.

44. Matthews RT, Kelly GM, Zerillo CA, Gray G, Tiemeyer M, Hockfield S. Aggrecan glycoforms contribute to the molecular heterogeneity of perineuronal nets. J Neurosci 2002; 22: 7536-7547.

45. Yamaguchi Y. Lecticans: organizers of the brain extracellular matrix. Cell Mol Life Sci2000; 57: 276-289.

46. Jaworski DM, Kelly GM, Hockfield S. BEHAB, a new member of the proteoglycan tandem repeat family of hyaluronan-binding proteins that is restricted to the brain. J Cell Biol 1994; 125: 495-509.
47. Yamada H, Watanabe K, Shimonaka M, Yamaguchi Y. Molecular cloning of brevican, a novel brain proteoglycan of the aggrecan/versican family. J Biol Chem 1994; 269: 10119-10126.

48. Frischknecht $\mathrm{R}$, Seidenbecher $\mathrm{Cl}$. Brevican: a key proteoglycan in the perisynaptic extracellular matrix of the brain. Int J Biochem Cell Biol 2012; 44: 1051-1054.

49. Spicer AP, Joo A, Bowling Jr RA. A hyaluronan binding link protein gene family whose members are physically linked adjacent to chondroitin sulfate proteoglycan core protein genes: the missing links. J Biol Chem 2003; 278: 21083-21091.

50. Saghatelyan AK, Gorissen S, Albert M, Hertlein B, Schachner M, Dityatev A. The extracellular matrix molecule tenascin-R and its $\mathrm{HNK}-1$ carbohydrate modulate perisomatic inhibition and long-term potentiation in the CA1 region of the hippocampus. Eur J Neurosci 2000; 12: 3331-3342.

51. Lundell A, Olin Al, Morgelin M, al-Karadaghi S, Aspberg A, Logan DT. Structural basis for interactions between tenascins and lectican C-type lectin domains: evidence for a crosslinking role for tenascins. Structure 2004; 12: 1495-1506.

52. Blosa M, Sonntag M, Bruckner G, Jager C, Seeger G, Matthews RT et al. Unique features of extracellular matrix in the mouse medial nucleus of trapezoid body-Implications for physiological functions. Neuroscience 2012; 228: 215-234.

53. Galtrey CM, Kwok JC, Carulli D, Rhodes KE, Fawcett JW. Distribution and synthesis of extracellular matrix proteoglycans, hyaluronan, link proteins and tenascin- $R$ in the rat spinal cord. Eur J Neurosci 2008; 27: 1373-1390.

54. Watanabe H, Nakata K, Kimata K, Nakanishi I, Yamada Y. Dwarfism and age-associated spinal degeneration of heterozygote $\mathrm{cmd}$ mice defective in aggrecan. Proc Natl Acad Sci USA 1997; 94: 6943-6947.

55. Quaglia X, Beggah AT, Seidenbecher C, Zurn AD. Delayed priming promotes CNS regeneration post-rhizotomy in Neurocan and Brevican-deficient mice. Brain 2008; 131: 240-249.

56. Czipri M, Otto JM, Cs-Szabo G, Kamath RV, Vermes C, Firneisz G et al. Genetic rescue of chondrodysplasia and the perinatal lethal effect of cartilage link protein deficiency. J Biol Chem 2003; 278: 39214-39223.

57. Paxinos G, Franklin KBJ. The Mouse Brain in Stereotaxic Coordinates. Academic Press: San Diego, CA, USA, 2001.

58. Rogakou EP, Pilch DR, Orr AH, Ivanova VS, Bonner WM. DNA double-stranded breaks induce histone H2AX phosphorylation on serine 139. J Biol Chem 1998; 273: 5858-5868.

59. Ohk TG, Yoo KY, Park SM, Shin BN, Kim IH, Park JH et al. Neuronal damage using fluorojade $\mathrm{B}$ histofluorescence and gliosis in the striatum after various durations of transient cerebral ischemia in gerbils. Neurochem Res 2012; 37: 826-834.

60. Schmued LC, Hopkins KJ. Fluoro-Jade B: a high affinity fluorescent marker for the localization of neuronal degeneration. Brain Res 2000; 874: 123-130.

(2) (3)(2) Cell Death and Disease is an open-access journal cc) published by Nature Publishing Group. This work is licensed under a Creative Commons Attribution-NonCommercialShareAlike 3.0 Unported License. To view a copy of this license, visit http://creativecommons.org/licenses/by-nc-sa/3.0/ 